Vietnam Academy of Science and Technology
(VAST) Vietnam Journal of Earth Sciences
http://www.vjs.ac.vn/index.php/jse

\title{
Estimation of errors in determination of main parameters of earthquake hypocenter, recorded by the national seismic network of Vietnam
}

\author{
Ngo Thi Lu'1,2*, Burmin V. Y. ${ }^{3}$, Phung Thi Thu Hang ${ }^{1,2}$, Vu Thi Hoan'1, Ha Thi Giang ${ }^{1}$ \\ ${ }^{1}$ Institute of Geophysics, Vietnam Academy of Science and Technology, Hanoi, Vietnam \\ ${ }^{2}$ Graduate University of Science and Technology, Hanoi, Vietnam \\ ${ }^{3}$ Institute of Physics of the Earth, Russian Academy of Sciences. 10, B. Gruzinskaya st., 123995, Moscow, \\ Russia
}

Received 8 June 2017; Received in revised form 27 October 2017; Accepted 10 November 2017

\begin{abstract}
In this paper the authors present the error estimation in determining main parameters of earthquake hypocenter based on solving the system of linear equations, expressing the relationship between earthquake coordinates and the coordinates of the seismic stations. The results of the error estimation in determining the epicenter coordinates and the focus depth of the earthquakes recorded by the system of 30 seismic stations in Vietnam are presented, interpreted and compared with the results of the previous studies.

The results show that the operation of the seismic network of Vietnam is not really optimal, particularly when determining the epicenter coordinates and the focus depth of the earthquakes in the East Vietnam Sea region.

The national seismic network of Vietnam allows determination of the epicenter coordinates and the focal depth of earthquakes for most of the Vietnam territory with the errors $\Delta \mathrm{h} \leq 20 \mathrm{~km}, \Delta \varphi \leq 4 \mathrm{~km}, \Delta \leq 5 \mathrm{~km}$. The errors of the determination of the epicenter coordinates and the focal depth of the earthquakes are increasing to the south and southwest areas of the territory of Vietnam and reach the maximum in these areas. Particularly, errors of the determination of the epicenter coordinates $(\Delta \varphi, \Delta \lambda)$ and the focal depth $(\Delta \mathrm{h})$ of earthquakes increase very rapidly toward the East Sea of Vietnam and reach the maximum in the region between the longitudes of $116-118^{\circ} \mathrm{E}$.

The Vietnam seismic network allows determining the epicenter coordinates and the focal depth of earthquakes in the Northern Vietnam with the smaller errors than in Central and Southern Vietnam, and this fact proves that the distribution of seismic network in the Northern Vietnam is more optimal than the station networks in the Central and Southern Vietnam. Therefore, in order to improve the effectiveness of the Vietnam seismic network, more seismic stations need to be added to the Central and Southern Vietnam.
\end{abstract}

Keywords: Error; estimation of errors; parameter; earthquake hypocenter; seismic network.

(C)2018 Vietnam Academy of Science and Technology

\section{Introduction}

Earthquakes in Vietnam are related mainly

*Corresponding author, Email: ngothiluigp@gmail.com with principal active fault zones like Dien Bien Phu fault, Son La fault, Red river fault, Ca River fault. Active fault segmentations are determined from geological, geophysical or 
Ngo Thi Lu, et al./Vietnam Journal of Earth Sciences 40 (2018)

geomorphological data (Nguyen Van Hung et al., 2016). The main parameters (coordinates, the focal depth and magnitude) of earthquakes are important characteristics for the estimation of the maximum earthquake in the studied region (Bui Van Duan et al., 2013). The project entitled "Enhancing the seismic network for earthquake prediction and tsunami warning in Vietnam" was started in 2008 and finished at the end of 2016 with a total of 30 seismic stations in the whole territory of Vietnam. Up to now, the network of 30 national seismic stations of Vietnam is in operation. However, there have been no studies on the evaluation of the effectiveness of the above seismic stations; as a result, the accuracy of the earthquake hypocenter parameters recorded by this network has not yet been clarified. Therefore, the error estimation in determining the main parameters of earthquake hypocenter (epicenter coordinates $(\Delta \varphi, \Delta \lambda)$, focal depth $(\Delta \mathrm{h}))$ recorded by the seismic network of Vietnam is not only a very important and necessary task in the seismology of Vietnam but also the basis for the verification and examination of the results and outputs of the project "Enhancing the seismic network for earthquake prediction and tsunami warning in Vietnam". Thus, the calculations in this study will be applied to the network of 30 seismic stations according to the station list of this project and this network will be called the national seismic network of Vietnam.

The objective of this study is to estimate the errors in determining main parameters of earthquake hypocenter, recorded by the seismic station network in the whole territory of Vietnam, for the purpose of evaluating the effectiveness of this network. It means that it is necessary to carry out the above task in order to answer the question: Can the main parameters of earthquake hypocenter be accurately determined from the seismograms recorded by the national seismic network of Vietnam and what is the minimum error?

The evaluation of effectiveness and optimal planning of seismic network have been considered and conducted by different authors in a variety of studies (Aranovich Z.I., 1977; 1980; Burmin V. Yu., 1976; 1986; 1992; 1994; Ngo, 1990, 1999; Nguyen Quy Hy et al., 1979; Savarenski E. F. et al., 1979; Iosif T. et al., 1972; 1974; Kijko A., 1975; 1978; 1980; Marshall A. W. et al., 1965; 1969; Sato and Skoko, 1965; Sato and Ochi 1967; Skoko D. et al., 1966; 1968; Uhrhammer R. A., 1980; 1982; Burmin V. Yu. et al., 2001; 2009).

For the territory of Vietnam, the same task has been carried out in several works (Burmin V. Yu., Ngo et al., 1992; Ngo, 1990; Nguyen Quy Hy, Pham Van Thuc et al., 1979; Burmin V. Yu. et al., 2009). In the works done by Burmin V. Yu., Ngo et al., 1992; Ngo, 1990, the authors conducted the geometric analysis of seismic network and determined the optimal locations for adding seismic stations in Northern Vietnam according to the approach proposed in Burmin V. Yu., 1976; 1986. In the work by Nguyen Quy Hy et al., 1979, the task of optimizing the seismic network in Vietnam territory was solved by the method of experimental seismic planning.

The authors of work (Burmin V. Yu. et al., 2009) evaluated the effectiveness of seismic network in Northern Vietnam at that time by calculating errors in the determination of main parameters of earthquake hypocenter. Consequently, the authors proposed the optimal seismic network in Northern Vietnam including 14 stations.

In this study, we calculate the errors in the determination of earthquake hypocenter parameters, recorded by the seismic network of 
Vietnam, for the purpose of evaluating the effectiveness of this network. We apply the approach that was proposed in Burmin V. Yu., 1986); Burmin V. Yu., Akhmechiev V. M., 1994) and implemented for the Northern Vietnam in Burmin V. Yu. et al., 2009.

\section{Theoretical basis of research methodology}

It is well known that the basis for the detailed and comprehensive study on seismicity in a territory is the collection of sufficiently reliable information on the main parameters of earthquake hypocenter in that territory. Then, the accuracy of solving seismological tasks is directly or indirectly related to the accuracy of determining main parameters of earthquake hypocenter.

The accuracy of determining main parameters of earthquake hypocenter in the heterogeneous environment is an extremely important problem, especially for the areas with complex geological and tectonic structures as the territory of Vietnam.

Practical experience and numerical calculations show that the accuracy of determining earthquake hypocenter parameters significantly depends on the positions of seismic stations relative to the earthquake hypocenters.

From the viewpoint of minimizing errors in the determination of earthquake hypocenter parameters, the seismic network with a given number of stations is considered to be optimal when errors in the determination of earthquake hypocenter parameters are minimal.

Accordingly, the basis for effectiveness evaluation or optimal planning of seismic station network in a certain territory is the system of equations, representing the relationship between the earthquake hypocenter coordinates and the coordinates of seismic stations as follows:

$\left(\mathrm{X}-x_{i}\right)^{2}+\left(\mathrm{Y}-y_{i}\right)^{2}+H^{2}=V_{i}^{2}\left(t_{i}-t_{o}\right)^{2}$ where $\mathrm{i}=1,2, \ldots, \mathrm{n}$ - the ordinal number of seismic stations; $\mathrm{x}_{\mathrm{i}}, \mathrm{y}_{\mathrm{i}}$ - the coordinates of seismic stations; X, Y, H - the coordinates of earthquake epicenter and focal depth; $t_{o}$ - time of earthquake occurrence; $t_{i}$ - travel time of seismic wave to the $i^{\text {th }}$ station. $V_{i}$ - seismic wave velocity (apparent velocity), calculated by the ratio between straight line distance from the $\mathrm{i}^{\text {th }}$ station to earthquake hypocenter and travel time of seismic wave along the distance.

In case $\mathrm{V}_{\mathrm{i}}$ is the function of variables $\mathrm{X}, \mathrm{Y}$, $\mathrm{H}, \mathrm{x}_{\mathrm{i}}, \mathrm{y}_{\mathrm{i}}$, the determination of earthquake hypocenter coordinates is very complicated. However, if considering the homogeneous environments or environments with constant velocity, the task of determining earthquake hypocenter coordinates is considerably simpler. Therefore, when solving the task of evaluating the effectiveness of seismic network and choosing the optimal locations of stations, the environment can be considered in a first approximation to be nearly the homogeneous one, it means $\mathrm{V}_{\mathrm{i}}=\mathrm{V}=$ Const.

When adding the parameter $\eta=X^{2}+Y^{2}+$ $\mathrm{H}^{2}-\mathrm{V}^{2} \mathrm{t}_{0}^{2}$, the system of equations (1) can be easily converted into the system of linear equations by grouping the unknowns as follows (Burmin V. Yu. et al., 2009):

$$
\mathrm{Xx}_{\mathrm{i}}+\mathrm{Yy}_{\mathrm{i}}+\mathrm{t}_{0} \mathrm{~V}_{\mathrm{i}}^{2} \mathrm{t}_{\mathrm{i}}+0.5 \eta=\mathrm{f}_{\mathrm{i}}
$$
where $\mathrm{i}=1,2, \ldots, \mathrm{n}$; with $\mathrm{n} \geq 3 ; \mathrm{f}_{\mathrm{i}}=0.5\left(\mathrm{x}_{\mathrm{i}}^{2}+\right.$ $\mathrm{y}_{\mathrm{i}}^{2}+\mathrm{V}^{2} \mathrm{t}_{\mathrm{i}}^{2}$;

The focal depth is determined by the following equation:

$$
\mathrm{H}^{2}=\eta-\mathrm{X}^{2}-\mathrm{Y}^{2}+\mathrm{V}^{2} \mathrm{t}_{0}{ }^{2}
$$

Equations (2) and (3) determine the coordinates $\mathrm{X}, \mathrm{Y}, \mathrm{H}$ and $\mathrm{t}_{0}$ on the condition that the seismic wave velocity is constant. To calculate the actual velocity distribution, we consider the iteration procedure. With the given values of $V_{i}$, the system of linear equations (1) can be converted into the form: 
Ngo Thi Lu, et al./Vietnam Journal of Earth Sciences 40 (2018)

$\mathrm{Xx}_{\mathrm{i}}+\mathrm{Yy}_{\mathrm{i}}-\mathrm{t}_{0} \mathrm{~V}^{2} \mathrm{t}_{\mathrm{i}}+0.5 \xi=\mathrm{f}_{\mathrm{i}}$

where $\mathrm{i}=1,2, \ldots, \mathrm{n} ; \xi=\mathrm{X}^{2}+\mathrm{Y}^{2}+\mathrm{H}^{2} ; \mathrm{f}_{\mathrm{i}}=0.5$ $\left[\left(\mathrm{x}_{\mathrm{i}}^{2}+\mathrm{y}_{\mathrm{i}}^{2}-\mathrm{V}_{\mathrm{i}}^{2}\left(\mathrm{t}_{\mathrm{i}}^{2}+\mathrm{t}_{0}^{2}\right)\right]\right.$.

To solve the system of equations (4), we need to give the value of $t_{0}$ in the right-hand side of (4). The first value of $t_{0}$ can be obtained when solving the system of equations (2). The obtained value of $t_{0}$ is added to the right-hand side of equation (4) in order to solve the system of equations. The obtained value of $t_{0}$ in the solution of the system of equations (4) is again added to the right-hand side of formula (4) and this equation is repeatedly solved. If the iteration process is convergent, it will provide the solution to the problem of determining earthquake hypocenter coordinates for the heterogeneous environment. Then, the errors of the required parameters (of the unknowns) will be determined only by the properties of system matrix and will be the errors of input data. It is easy to see that the matrices of systems of equations (2) and (4) differ only by the multipliers $\mathrm{V}$ and $\mathrm{V}_{\mathrm{i}}$. Then, we will write the systems of linear equations, which represent the relationships between earthquake hypocenter coordinates, the seismic wave velocity, and the time at hypocenter, in a matrix form as follows:

$$
\mathrm{KP}=\mathrm{f}
$$

where $\mathrm{K}=\left\{\mathrm{k}_{\mathrm{ij}}\right\}$ - is the matrix of the system, representing the mathematical model of the studied dependence. $P^{\mathrm{T}}=\left\{\mathrm{p}_{\mathrm{j}}\right\}=\left\{\mathrm{X}, \mathrm{Y}, \mathrm{t}_{0}, \xi\right\}$ - is the column vector of sought parameters; $f$ $\mathrm{T}=\left\{\mathrm{f}_{\mathrm{i}}\right\}-$ is the column vector of observed quantities; $i=1,2, \ldots, n ; j=1,2, \ldots, m ; n \geq m$.

The solution of equation (5) is found by the least squares method and given by the following formula:

$$
\mathrm{P}=\mathrm{K}^{+} \mathrm{f}
$$

Where $\mathrm{K}^{+}$is the generalized inverse matrix, in this case $\mathrm{K}^{+}=\left(\mathrm{K}^{+} \mathrm{K}\right)^{-1} \mathrm{~K}^{\mathrm{T}}$.
The estimation (3) is true for the error of total vector of unknown parameters in the system of equations:

$\|\Delta p\|=\left\{\sum_{i=1}^{n}\left|\Delta p_{i}\right|^{2}\right\}^{1 / 2} \leq\left\|\widetilde{K}^{+}\right\| \cdot\|R v \rho\| .\|\Delta t\|$

Where $\|R v \rho\|=\left\{\sum_{i=1}\left|R_{i} v_{i} \rho_{i}\right|^{2}\right\}^{1 / 2} ; \rho_{i}$ - is the weight, characterizing the quality of recording in the $\mathrm{i}^{\text {th }}$ station; $\mathrm{R}$ - is the vector whose components are the corresponding epicenter distances; $|\Delta t|$ - is the absolute value of the error in determining the travel time of seismic wave to the station. The characteristics of the errors can be different. The errors can be random or systematic, estimated by the deviation between the value of the apparent velocity of seismic wave $\mathrm{V}_{\mathrm{i}}$ used in the calculation and the actual value.

The objective function $J_{0}=\left\|\widetilde{K}^{+}\right\| \cdot\|R v \rho\|$ determines the accuracy of earthquake hypocenter parameters; essentially, it characterizes the quality of seismic station network. The quantity $\mathrm{J}_{0}$ is the objective function corresponding to earthquake hypocenter parameters $\left(\mathrm{J}_{0}(\Delta \varphi, \Delta, \Delta \mathrm{h})\right)$ and is the error of total deviation vector when $|\Delta \mathrm{t}|=1$ second. When changing the locations of different seismic stations and calculating the corresponding values of the function $\mathrm{J}_{0}$, it is possible to indicate the seismic network that ensures the highest accuracy in earthquake positioning. More details on the theoretical basis of the method can be found in (Burmin V. Yu., 1986; Burmin V. Yu. et al., 1994; 2009).

Thus, the evaluation of the effectiveness of seismic network is essentially the task of minimizing the error values in the determination of unknown quantities (earthquake epicenter coordinates and focal depth) from equation (6) or minimizing the values of objective function $\mathrm{J}_{0}$.

The specific task in this study is to estimate the errors in determining main parame- 
Vietnam Journal of Earth Sciences, 40(1), 1-16

ters of earthquake hypocenter, recorded by the work are known. The main parameters and the seismic network of Vietnam. Therefore, the sketch map of the seismic network of Vietnam coordinates of all seismic stations in the net- are presented in Table 1 and Figure 1.

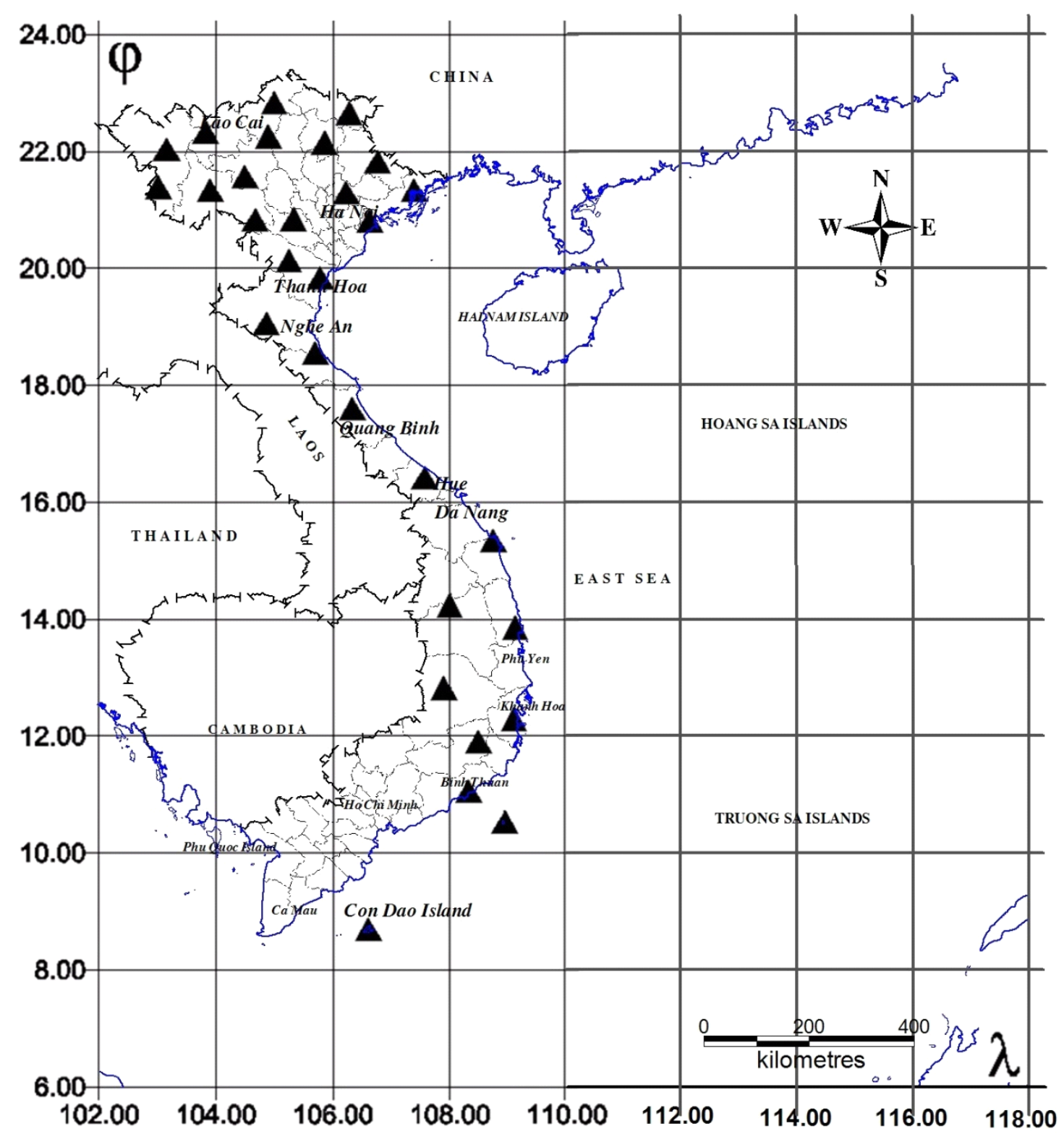

Figure 1. Plan of the existing national seismic network of Vietnam $(\Delta \varphi)(\mathrm{km})(\boldsymbol{\Lambda}$ - Seismic station) 
Ngo Thi Lu, et al./Vietnam Journal of Earth Sciences 40 (2018)

Table 1. Main parameters of seismic network of Vietnam

\begin{tabular}{|c|c|c|c|c|c|}
\hline \multirow{2}{*}{ No. } & \multirow{2}{*}{ Station code } & \multicolumn{2}{|c|}{ Station coordinates } & \multirow{2}{*}{ Station name } & \multirow{2}{*}{ Elevation (m) } \\
\hline & & Longitude & Latitude & & \\
\hline 1 & SPVO* & 103.83000 & 22.33300 & $\mathrm{Sa} \mathrm{Pa}$ & 1550 \\
\hline 2 & DBVB & 103.01800 & 21.39000 & Dien Bien & 480 \\
\hline 3 & SLV & 103.90500 & 21.33400 & Son La & 607 \\
\hline 4 & HBVB & 105.3277 & 20.8422 & Hoa Binh & 54 \\
\hline 5 & BGVB & 106.22700 & 21.29000 & Bac Giang & 13 \\
\hline 6 & PLVO* & 106.63000 & 20.80600 & Phu Lien & 5 \\
\hline 7 & VIVO* & 105.70000 & 18.54800 & Vinh & -6 \\
\hline 8 & DLV & 108.48300 & 11.90000 & Da Lat & 1530 \\
\hline 9 & HGVB & 104.99238 & 22.83507 & Ha Giang & 119 \\
\hline 10 & BCVB & 105.85632 & 22.14992 & Bac Kan & 112 \\
\hline 11 & CBVB & 106.27118 & 22.65752 & Cao Bang & 239 \\
\hline 12 & MCVB & 104.67170 & 20.83468 & Moc Chau & \\
\hline 13 & LSVB & 106.76225 & 21.82510 & Lang Son & 285 \\
\hline 14 & TYVB & 107.38933 & 21.33467 & Tien Yen & 37 \\
\hline 15 & LAVB & 105.24765 & 20.13587 & Lang Chanh & 53 \\
\hline 16 & THVB & 105.78355 & 19.84475 & Thanh Hoa & 1 \\
\hline 17 & CCVB & 104.85583 & 19.05707 & Con Cuong & 30 \\
\hline 18 & HUVB & 107.56890 & 16.41553 & Hue & 8 \\
\hline 19 & BMVB & 107.89300 & 12.81900 & Buon Me Thuot & \\
\hline 20 & NHAV & 109.09236 & 12.30376 & Nha Trang & 5 \\
\hline 21 & BTVB & 108.31845 & 11.05338 & Binh Thuan & \\
\hline 22 & PQVB & 108.93737 & 10.53500 & Phu Quy & \\
\hline 23 & CĐVB & 106.60147 & 8.69512 & Con Dao & \\
\hline 24 & MLAV & 103.15500 & 22.03900 & Muong Lay & 270 \\
\hline 25 & VTVB & 104.89850 & 22.25260 & Vinh Tuy & 71 \\
\hline 26 & VCVB & 104.49433 & 21.56901 & Van Chan & 274 \\
\hline 27 & QBVB & 106.32775 & 17.60315 & Quang Binh & \\
\hline 28 & QNVB & 108.74210 & 15.34753 & Quang Ngai & \\
\hline 29 & GLVB & 107.99212 & 14.23255 & Gia Lai & \\
\hline 30 & BĐVB & 109.11109 & 13.86446 & Binh Dinh & 10 \\
\hline
\end{tabular}

3. Result: Error estimation in determining main parameters of earthquake hypocenter recorded by the seismic network of Vietnam

\subsection{Input data for the calculation}

When estimating the errors in the determination of main parameters of earthquake hypocenter recorded by the existing seismic network in the whole territory of Vietnam, we have used the following input data:

- The coordinates and parameters of 30 seismic stations presented in Table 1.

- The model of seismic wave velocity in the Earth's crust, appropriate for the real environment in Vietnam, obtained from Ngo et al., 2014.
It should be noted that the model of seismic wave velocity in the Earth's crust proposed by Ngo et al., 2014 is applied to the depth of Moho boundary. However, according to the requirement of the project "Enhancing the seismic network for earthquake prediction and tsunami warning in Vietnam", the station network should be able to detect the earthquakes with magnitude $\mathrm{M} \geq 3.5$ in the whole territory of Vietnam and with $\mathrm{M} \geq 6.5$ in the whole area of the East Vietnam Sea. Therefore, we need to calculate and establish the distribution sketch maps of error values in determining main parameters of earthquake hypocenter, which can be recorded by the exist- 
ing seismic network in the Vietnam territory, for the East Vietnam Sea area. The model of seismic wave velocity obtained from Ngo et al., 2014 only meets this requirement at close distance (800-1000 km from seismic station). Accordingly, based on the combination of three velocity models obtained in the studies by Ngo et al., 2014; Burmin et al., 2001; 2009), we have presented the model in Table 2 that ensures both the characteristics of local velocity model and the characteristics of regional velocity model (Table 2).

Table 2. Velocity model used in the calculation Accor ing to Ngo et al., 2014; Burmin et al., 2001; 2009

\begin{tabular}{ccccc}
\hline Layer & $\begin{array}{c}\text { Depth of lay- } \\
\text { er boundary } \\
(\mathrm{km})\end{array}$ & $\begin{array}{c}\text { Velocity on the } \\
\text { surface of } \\
\text { boundary } \\
(\mathrm{km} / \mathrm{s})\end{array}$ & $\begin{array}{c}\text { Velocity at the } \\
\text { bottom of } \\
\text { boundary } \\
(\mathrm{km} / \mathrm{s})\end{array}$ \\
\cline { 1 - 1 } 2 & 2.0 & 2.80 & 2.85 \\
3 & 3.0 & & 4.00 & 4.05 \\
4 & 21.0 & 6.20 & 6.30 \\
5 & 24.0 & 6.90 & 7.20 \\
6 & 80.0 & 8.00 & 8.30 \\
7 & 130.0 & 8.30 & 8.50 \\
8 & 160 & 8.50 & 9.10 \\
\hline
\end{tabular}

3.2. Error estimation in determining main parameters of earthquakes hypocenters, recorded by the existing national seismic network in the whole territory of Vietnam

Error in determining the focal depth $(\Delta h)$

With the above input data, after many experimental calculations, we have established the sketch map of the distribution of error values in determining focus depth $(\Delta \mathrm{h}, \mathrm{km})$ which can be recorded by the existing national seismic network in the whole territory of Vietnam. The calculated results are presented in Figure 2. The analysis of the results in Figure 2 shows that:

The seismic network of Vietnam allows the determination of focal depth in most of Vietnam territory with the error $\Delta \mathrm{h} \leq 20 \mathrm{~km}$ and the maximum error $\Delta \mathrm{h}$ max up to $130 \mathrm{~km}$ in the East Vietnam Sea area ( within the area between the longitudes of $116-118^{\circ} \mathrm{E}$ ).

The error in determining focal depth gradually increases toward the south of Vietnam and reaches the maximum in the Southern region with $\Delta \mathrm{h}=30 \sim 40 \mathrm{~km}$.

In the Northern and Central regions, the error in determining focal depth seems to be smaller $(\Delta \mathrm{h} \leq 10 \mathrm{~km})$; however, in the Southern region and especially in the southwest of this region, the error in determining focal depth is higher; at some locations, the value of $\Delta \mathrm{h}$ is $40 \mathrm{~km}$ or greater.

The values of the isolines of errors in determining focal depth $\Delta \mathrm{h}$ increase rapidly toward the East Vietnam Sea and reach $\Delta \mathrm{h}=$ $130-150 \mathrm{~km}$ in the region within longitudes of $116-118^{\circ} \mathrm{E}$. It means that from the viewpoint of evaluating the effectiveness of station network based on the error estimation in determining focal depth, the network of 30 stations of Vietnam is not really optimal, especially when determining the focal depth of earthquakes outside the Vietnam territory in the East Sea area.

Errors in determining the epicenter coordinates in latitude $(\Delta \varphi)$ and in longitude $(\Delta \lambda)$

After many experimental calculations, we have established the sketch map of the distribution of error values in determining epicenter coordinates in latitude $(\Delta \varphi)$ and in longitude $(\Delta \lambda)$ which can be recorded by the existing national seismic network in the whole territory of Vietnam. The results are presented in Figures 3, 4. The analysis of the results in Figures 3 and 4 shows that:

With the existing seismic network, it is possible to record and determine the epicenter coordinates in latitude $(\Delta \varphi)$ and in longitude $(\Delta \lambda)$ in most of Vietnam territory with the errors $\Delta \varphi \leq 4 \mathrm{~km}, \Delta \lambda \leq 5 \mathrm{~km}$. The largest errors 
Ngo Thi Lu, et al./Vietnam Journal of Earth Sciences 40 (2018)

for latitude ( $\Delta \varphi \max )$ reaches $14-16 \mathrm{~km}$ and the East Vietnam Sea (within the area befor longitude ( $\Delta \lambda \max )$ reaches $35-40 \mathrm{~km}$ in tween the longitudes of $116-118^{\circ} \mathrm{E}$ ).

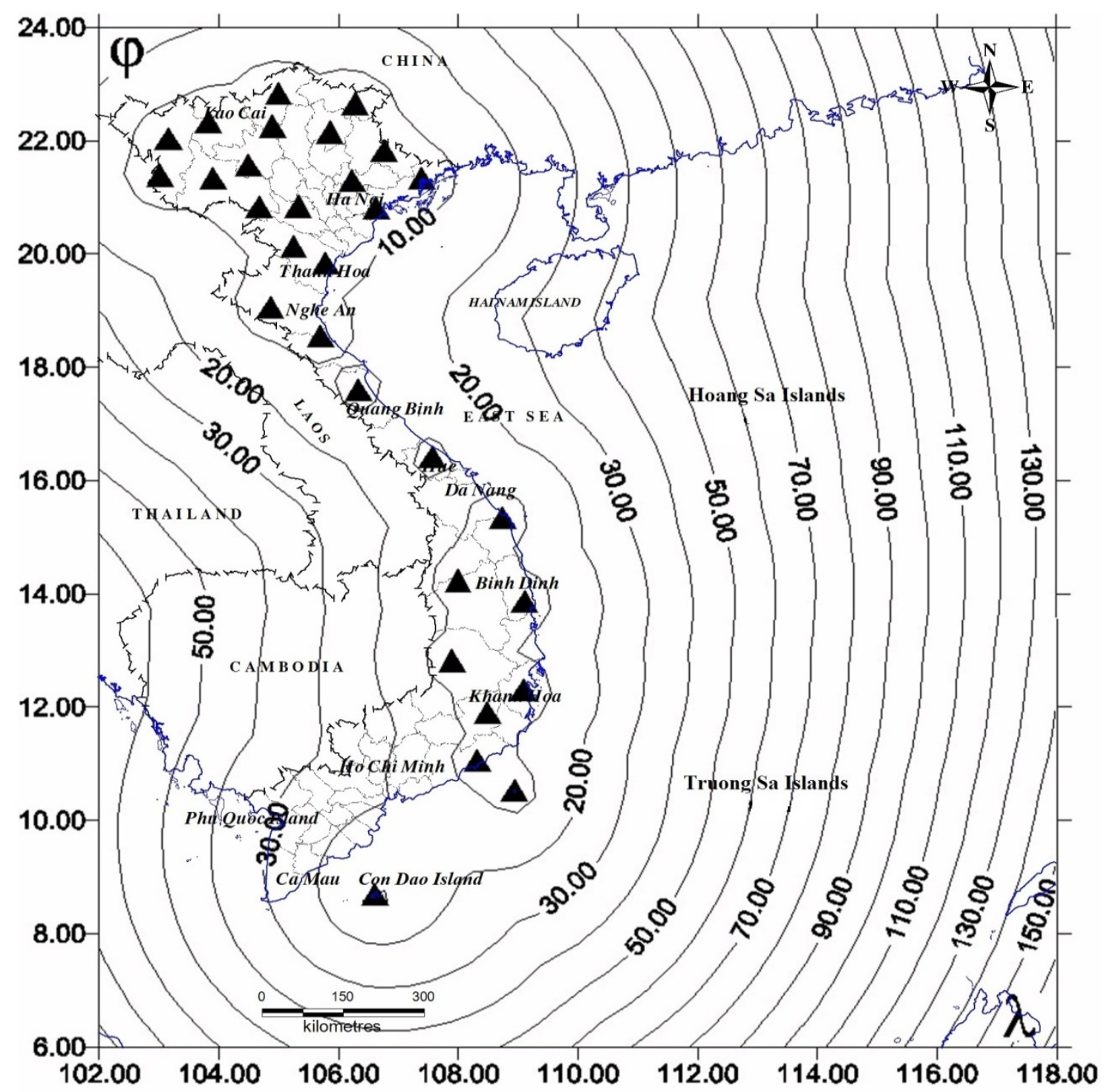

Figure 2. Error distribution in determination of the depth of earthquake hypocenter for the existing seismic network of Vietnam $(\Delta \mathrm{h})$

$\boldsymbol{\Delta}$ - Seismic station; 3.0 hypocenter for the existing seismic network of Vietnam $(\Delta \mathrm{h})(\mathrm{km})$ 


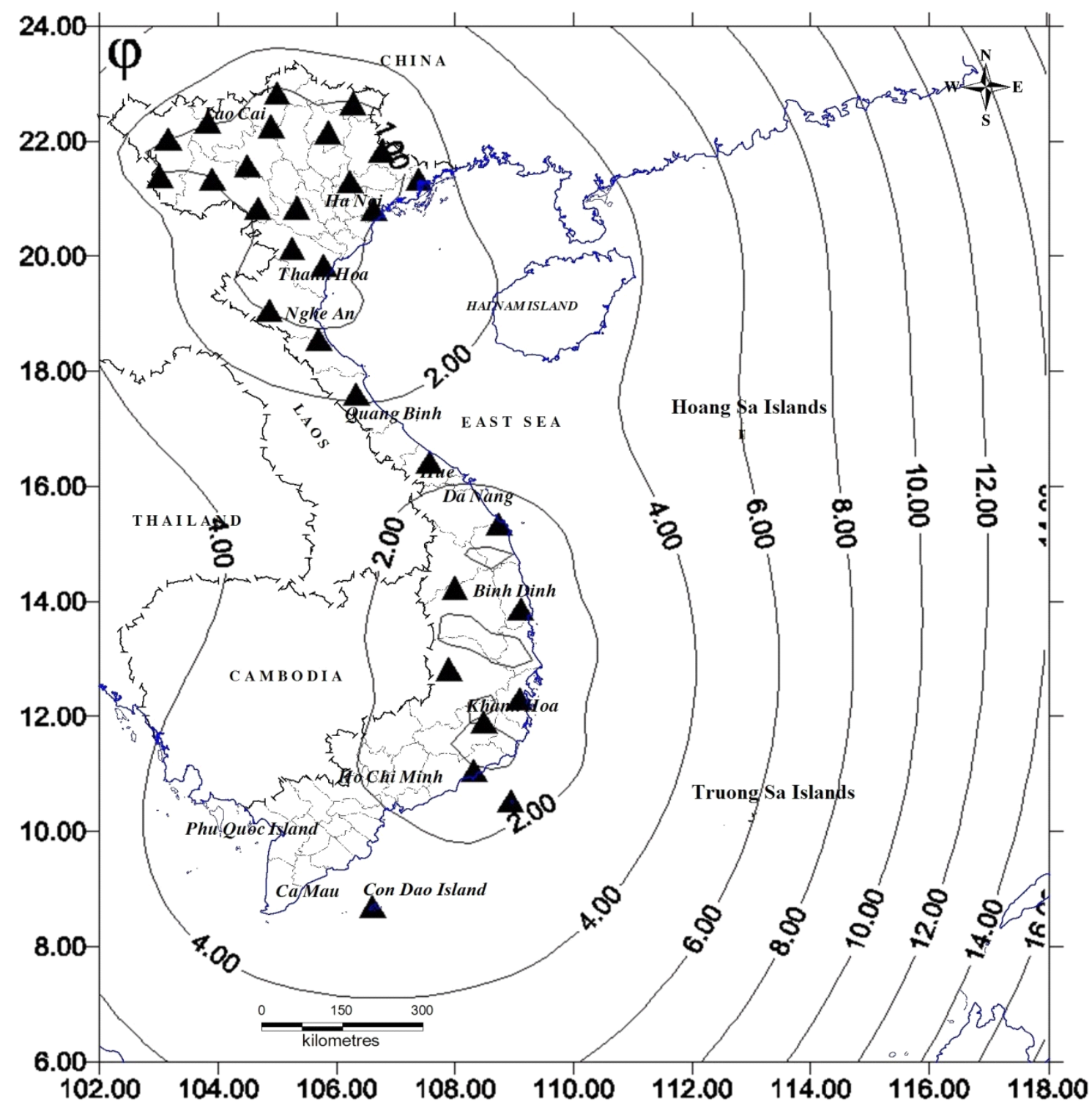

Figure 3. Error distribution in determination of $Y$ coordinate of hypocenter for the existing seismic network of Vietnam; $\boldsymbol{\Delta}$ - Seismic station; - Isoline of errors in determination of Y coordinate of hypocenter for

The errors in determining epicenter coordinates in latitude $(\Delta \varphi)$ and in longitude $(\Delta \lambda)$ increase toward the south and southeast of Vietnam, reaching the maximum in the Southern region with $\Delta \varphi \max =4 \mathrm{~km}, \Delta \lambda \max$ $=5 \mathrm{~km}$.
In the Northern and Central regions, the errors in determining epicenter coordinates are smaller $(\Delta \varphi \leq 2 \mathrm{~km}, \Delta \lambda \leq 2.5 \mathrm{~km})$; however, in the Southern region and especially in the southwest of this region, the errors in determining epicenter coordinates in latitude and in longitude are higher; at some locations, $\Delta \varphi$ 
Ngo Thi Lu, et al./Vietnam Journal of Earth Sciences 40 (2018)

reaches $3 \mathrm{~km}$ or greater, and $\Delta \lambda$ reaches $5 \mathrm{~km}$ or greater.

The values of the isolines of errors in determining epicenter coordinates in latitude
$\Delta \varphi$ and in longitude $\Delta \lambda$ increase rapidly toward the East Vietnam Sea, and reach $\Delta \varphi=$ $14-16 \mathrm{~km}$ and $\Delta \lambda=35-40 \mathrm{~km}$ in the region within the longitudes of $116-118^{\circ} \mathrm{E}$.

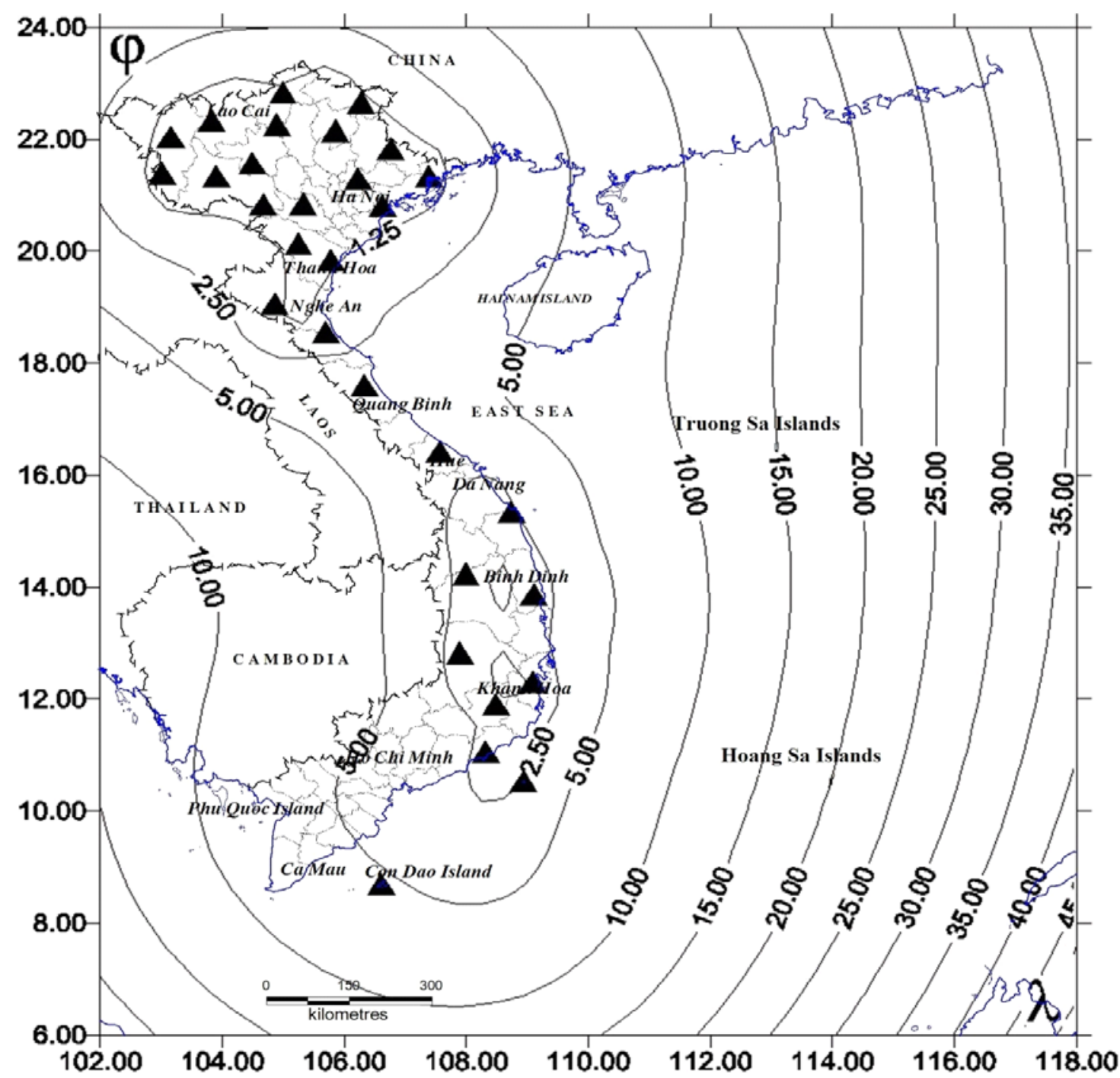

Figure 4. Error distribution in determination of $X$ coordinate of hypocenter for the existing seismic network of Vietnam $(\Delta \lambda)(\mathrm{km}) ; \boldsymbol{\Delta}$ - Seismic station; $3.0-$ Isoline of errors in determination of $\mathrm{X}$ coordinate of hypocenter for the existing seismic network of Vietnam $(\Delta \lambda)(\mathrm{km})$.

Thus, the results of the estimation of errors $\Delta \mathrm{h}, \Delta \varphi, \Delta \lambda$ show that from the viewpoint of evaluating the effectiveness of seismic network based on the error estimation in deter- mining main parameters of earthquake hypocenter (epicenter coordinates $(\Delta \varphi, \Delta \lambda)$, focal depth $(\Delta \mathrm{h})$ ), recorded by the existing seismic network in the whole territory of Vietnam, the 
network of 30 stations of Vietnam is not really optimal, especially when determining epicenter coordinates and focus depth of the earthquakes in the East Vietnam Sea area. The existing seismic network allows determining epicenter coordinates and hypocenter depth in the Northern and Central regions with the smaller errors than in the Southern region.
To verify the accuracy of the above remark, we have divided the studied territory into three regions including the Northern, Central and Southern regions of Vietnam and estimated the error in determining focal depth $(\Delta \mathrm{h})$ for each region. The results are presented in Figures 57, respectively. The captions of Figures 6,7 are similar to the caption of Figure 5.

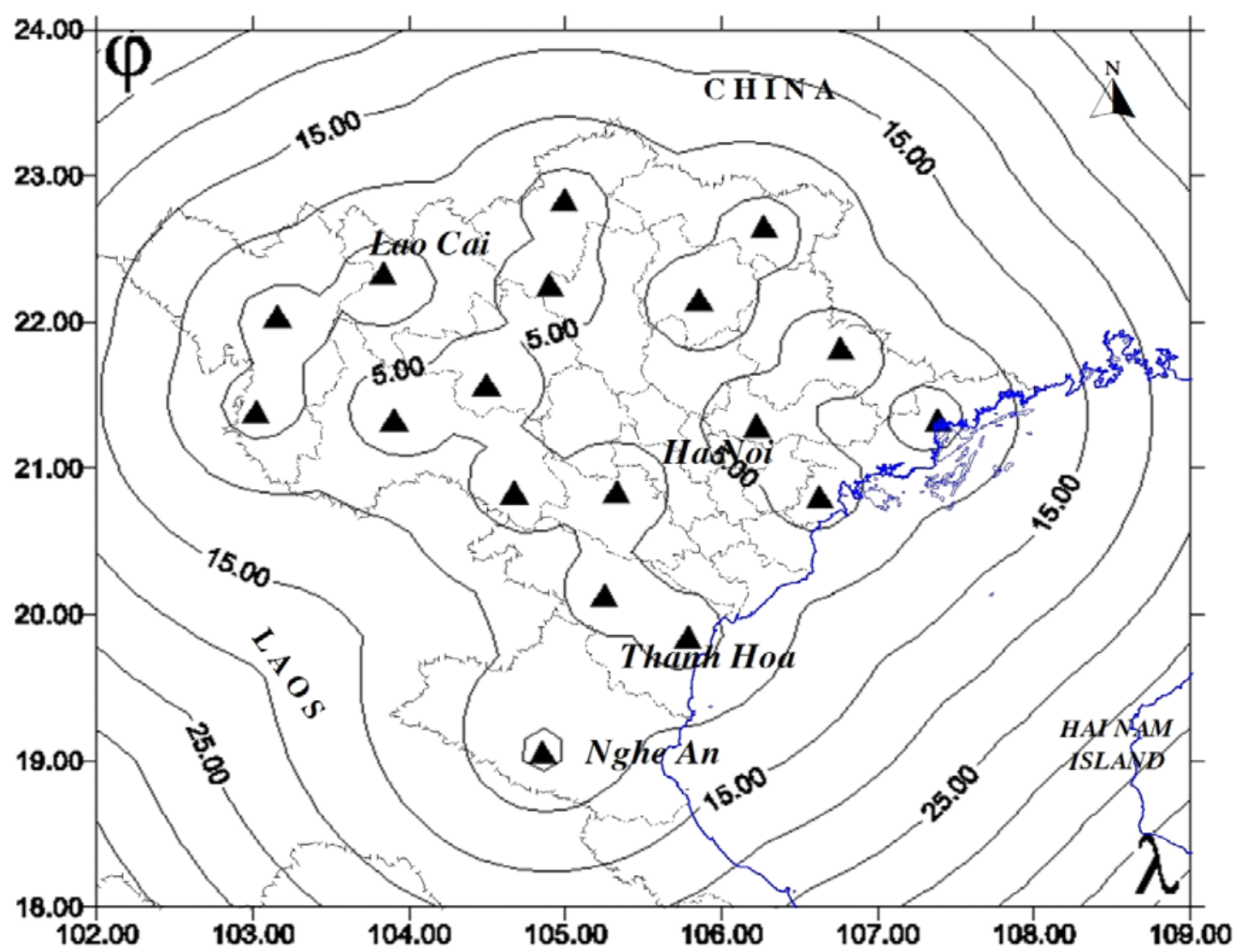

Figure 5. Error distribution in determination of the depth of earthquake hypocenter for the existing seismic network in the North of Vietnam $(\Delta \mathrm{h}) ; \boldsymbol{\Delta}$ - Seismic station; of earthquake hypocenter for the existing seismic network in the North of Vietnam $(\Delta \mathrm{h})(\mathrm{km})$ 


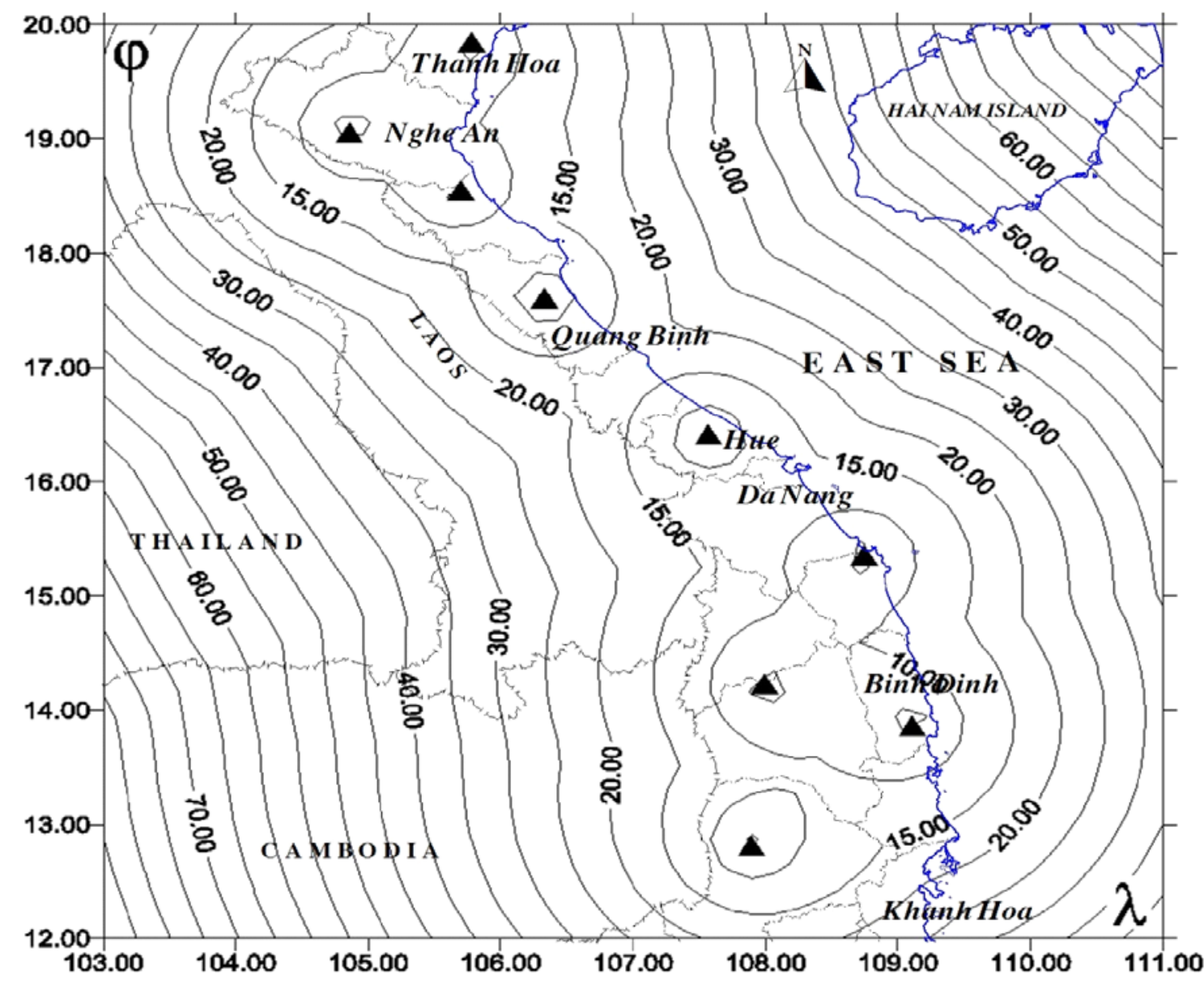

Figure 6. Error distribution in determination of the depth of earthquake hypocenter for the existing seismic network in the Central region of Vietnam $(\Delta \mathrm{h})$

The analysis of the calculated results in Figures 5-7 shows that the seismic network in the Northern Vietnam is relatively dense, the stations are evenly distributed in distance; therefore, the result of error estimation in determining focus depth $(\Delta \mathrm{h})$ is not significantly high and acceptable $(\Delta \mathrm{h} \leq 25 \mathrm{~km})$. However, the calculated results for the seismic network in the Central and Southern regions of Vietnam show that the seismic stations in these two regions are inappropriately distributed, the number of stations is smaller than in the Northern region and uneven in distance. In the Central region, the stations are distributed in a nearly straight line in the north-south direction, so the error values in determining focus depth $(\Delta \mathrm{h})$ are significantly higher than the corresponding results in the Northern region. In the Southern region, there are no seismic stations in the south and southwest of this region, so the error values in determining focus depth $(\Delta \mathrm{h})$ increase quite rapidly toward these directions, reaching $\Delta \mathrm{h}=50 \mathrm{~km}$ in some locations. In addition, the isolines of errors obtained in Figure 5 are distributed relatively evenly while those obtained in Figures 6 and 7 are distributed with the more tortuous shape and closer to each other than the results in Figure 5. 
The error estimation in determining epicenfor the Northern, Central and Southern regions ter coordinates $(\Delta \varphi, \Delta \lambda)$ has been conducted and the same results have been obtained.

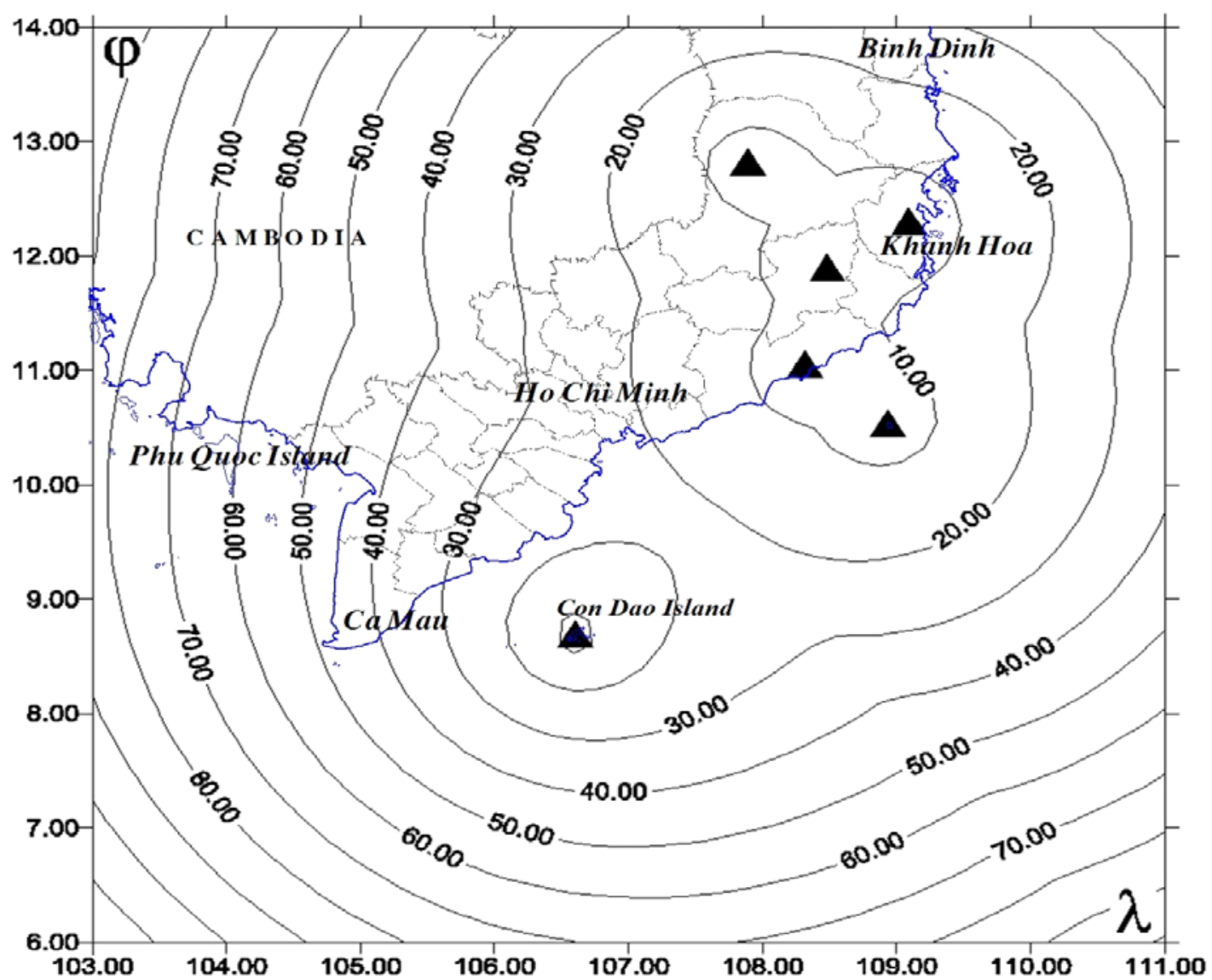

Figure 7. Error distribution in determination of the depth of earthquake hypocenter for the existing seismic network in the South of Vietnam $(\Delta \mathrm{h})$

\section{Discussions}

The above results show that the seismic network in the Northern region allows recording and determining earthquake hypocenter parameters with the smaller errors than in the Central and Southern regions. It means that the seismic network in the Northern region is more optimal than in the Central and Southern regions.

However, it should be noted that in comparison with the optimal seismic network (including 14 stations) proposed for Northern Vietnam in Burmin V. Yu. et al., 2009, the existing seismic network in Northern Vietnam (including 18 stations) allows recording and determining earthquake hypocenter parameters in most of this region with the same values of errors of epicenter coordinates $(\Delta \varphi \leq$ $4 \mathrm{~km} ; \Delta \lambda \leq 5 \mathrm{~km})$, but the error of focal depth is higher $(\Delta \mathrm{hmax}=25 \mathrm{~km})$ compared to the optimal seismic network proposed in Burmin V. Yu. et al., $2009(\Delta \mathrm{hmax}=14 \mathrm{~km})$. It means that from the viewpoint of evaluating the effectiveness of seismic network, the existing seismic network in the Northern region is denser than the optimal seismic network (only 
Ngo Thi Lu, et al./Vietnam Journal of Earth Sciences 40 (2018)

including 14 stations) proposed in Burmin V. Yu. et al., 2009. Thus, the existing seismic network in the Northern region is not really economically effective compared to the optimal seismic network proposed in Burmin V. Yu. et al., 2009 due to the extra cost of equipment purchase, installation and operation for 4 additional seismic stations.

Therefore, in order to improve the effectiveness of the seismic network of Vietnam, a number of stations should be added to the Central and Southern regions of Vietnam. In addition, in order to economize, it is possible to reduce 4 stations out of 18 existing stations in the Northern region (if necessary).

\section{Conclusions}

The results of error estimation of epicenter coordinates and focal depth, recorded by the national network of 30 seismic stations of Vietnam allow drawing the following conclusions:

The existing national seismic station network of Vietnam allows determining epicenter coordinates and focus depth in most of Vietnam territory with the errors $\Delta \mathrm{h} \leq 20 \mathrm{~km}$, $\Delta \varphi \leq 4 \mathrm{~km}, \Delta \lambda \leq 5 \mathrm{~km} ; \Delta \mathrm{hmax}$ reaches $130 \mathrm{~km}, \Delta \varphi \max$ reaches $14-16 \mathrm{~km}$, and $\Delta \lambda$ max reaches $35-40 \mathrm{~km}$ in the East Vietnam Sea area (in the area between the longitudes of $\left.116-118^{\circ} \mathrm{E}\right)$.

The values of errors in determining epicenter coordinates and focus depth increase toward the south and southwest of Vietnam and reach the maximum in the Southern region with $\Delta \mathrm{hmax}=40 \sim 50 \mathrm{~km}, \Delta \varphi \max =4 \mathrm{~km}$, $\Delta \lambda \max =5 \mathrm{~km}$.

The values of the isolines of errors in determining epicenter coordinates $(\Delta \varphi, \Delta \lambda)$ and focus depth $(\Delta \mathrm{h})$ increase rapidly toward the East Vietnam Sea, and reach the maximum in the region within the longitudes of $116-118^{\circ} \mathrm{E}$.

From the viewpoint of evaluating the effectiveness of seismic network based on the error estimation in determining main parame- ters of earthquake hypocenter (epicenter coordinates $(\Delta \varphi, \Delta \lambda)$, focal depth $(\Delta \mathrm{h}))$, recorded by the existing national seismic network of Vietnam, this network is not really optimal, especially when determining epicenter coordinates and focal depth of the earthquakes in the East Vietnam Sea area.

The national seismic network of Vietnam allows determining epicenter coordinates and focus depth in the Northern region with the smaller errors than in the Central and Southern regions. It means that the seismic network in the Northern region is more optimal than in the Central and Southern regions. Therefore, in order to improve the effectiveness of the national seismic network of Vietnam, a number of stations should be added to the Central and Southern regions of Vietnam.

\section{Acknowledgements}

This article is completed with the support of the scientific and technological project of Vietnam Academy of Science and Technology (VAST05.03/16-17). The authors gratefully thank for this support.

\section{References}

Aranovich Z.I., 1980. On the method of selecting the optimal positions of seismic stations in the local network. //Methodologies and assessment results of the effectiveness of the regional seismic network. Tbilisi: Mesnhiereba, 150-157 (in Russian).

Aranovich Z.I., Akhalbedasvili A.M., Gosadze O.D. et al., 1977. The methodologies of evaluating the effectiveness of regional seismic network, in case of the Caucasus region.//The issues of optimization and automation of seismic observations. Tbilisi: Mesnhiereba, 27-57 (in Russian).

Bui Van Duan, Nguyen Cong Thang, Nguyen Van Vuong, Pham Dinh Nguyen, 2013. The magnitude of the largest possible earthquake in the Muong LaBac Yen fault zone. J. Sci. of the Earth, 35, 53-49.

Burmin V. Yu., 1976. The task of experimental planning and the estimation of the system of linear 
algebraic equations.//The USSR Academy of Sciences Publishing House. Cybernetics, 2, 195-200.

Burmin V. Yu., 1986. The optimal distribution of seismic stations when recording near earthquakes.//The USSR Academy of Sciences Publishing House. Geophysics. Moscow, 5, 34-42 (in Russian).

Burmin V. Yu., Akhmechiev V.M., 1994. The errors in determining parameters of near earthquake hypocenter and the effectiveness of seismic network.//Journal of Volcanology and Seismology. Moscow, 2, 109-128 (in Russian).

Burmin V. Yu., Ngo TL., Kondorskaia N.V. and Akhmechiev V.M., 1992. The geometric analysis of existing seismic network in the Northern Vietnam.//The news from Russian Academy of Sciences. Journal of Geophysics. Moscow, 6, 123-128 (iIn Russian).

Burmin V. Yu., Ngo T.L., Tran V.P., 2009. Estimation of efficiency of seismic stations modern network and design of an optimal one on the territory of Vietnam.// Journal "Seismic Instruments”, 45(1), 27-35.

Burmin V. Yu., Nguyen VP., 2001. Planning to optimum regional network of the seismological observations for South- East Asia.//Journal "Volcanology and Seismology", 1, 68-75.

Iosif T. and Iosif S., 1974. Optimization of seismic stations distribution in Romania.//Studii si cercetari de geofisica, 12, 51-88.

Iosif T., Skoko D. and Sato Y., 1972. Optimum distribution of seismic stations in Romania.//Bull. Int. seism. Earthq. Eng, 9, 121p.

Kijko A., 1975. On optimal extensions of regional networks of seismic stations - Publs. Inst. Geophys. Pol. Acad. Sci., 96, 57-119.

Kijko A., 1978. Method of the optimal planning of regional seismic networks.//Polish Academy of Sci. publication of the inst. Of geoph. A-7 (119). Panctwowe wydawnictwo naukowe. Warszawa; Lodz, 63p.

Kijko A., 1980. Optimum seismic networks in the Ostrova coal basin.//Czechoslovakia. Acta montana UGG CSAV. Praha, 55, 73-95.
Marshall A.W., Olkin I., 1965. Norms and inequalities for condition numbers.//Pacific J. Math, 15, 241-247.

Marshall A.W., Olkin I., 1969. Norms and inequalities for condition numbers.//Linear Algebra and Application, 2(2), 167-172.

Marshall A.W., Olkin I., 1973. Norms and inequalities for condition numbers.//Linear Algebra and Application, 3(7), 191-300.

Ngo TL., 1990. Kinetic and dynamic parameters of earthquake hypocenter in the Northern Vietnam. The Candidate of Sciences Thesis on MathematicsPhysics, Speciality Geophysics. Institute of Geophysics, the USSR Academy of Sciences. Moscow, 133p (in Russian).

Ngo T.L., 1999. The characteristics of seismicity and the main features of earthquake hypocenter in the Southeast Asia from the viewpoint of clarifying the new tectonic structures. The Doctor of Science Thesis on Mathematics-Physics, Speciality Geophysics. Institute of Geophysics, the USSR Academy of Sciences. Moscow, 342p (in Russian).

Ngo T.L., 2005. The algorithm for improvement of velocity model of Earth's crust and hodographs of travel times of seismic waves in the territory of Vietnam. J. Sci. of the Earth, 27(1), 23-26.

Ngo T.L., 2005. The analysis of the seismic data for accounting hodographs of travel times of P-wave. J. Sci. of the Earth, 27, 374-377.

Ngo T.L., Tran V.P., Vu T.H., Le T.T., 2014. The establishment of velocity model and hodographs of travel times of seismic waves in the Earth's crust in the Northern, Central and Southern regions of Vietnam. Journal of Geology, Hanoi, Series A, 341-345, 355-365.

Nguyen Quy Hy, et al., 1979. Optimal addition of seismic network in the Vietnam territory by the method of seismic experimental planning.//The research results of "Earth Sciences" 1977-1978. Series Geophysics. Vietnam Academy of Science and Technology. Hanoi, 9-31 (in Vietnamese).

Nguyen Van Hung., Hoang Quang Vinh, Nguyen Van Huong, 2016. Tectono-structural system and geodynamic features of Northwest Vietnam in the late Ce- 
Ngo Thi Lu, et al./Vietnam Journal of Earth Sciences 40 (2018)

nozoic period. Vietnam J. Earth Sci., 38(1), 38-45. Doi: 10.15625/0866-7187/38/1/8408.

Sato Y., 1965. Optimum distribution of seismic observation points.//Zisin J. Seism. Soc. Japan, 18(1), 9-14.

Sato Y., Skoko D., 1965. Optimum distribution of seismic observation points II.//Bull. Earthquake. Res. Inst., 43(3), 451-458.

Sato Y., Ochi I., 1967. Accuracy of the determination of earthquake source parameters in and around Japan.//Bull. Earthq. Res. Inst., 45(1), 1-17.

Savarenski E.F., Shafronov V.V., Peskov A.B. et al., 1979. Optimal planning of seismic stations from the viewpoint of minimizing error in the epicenter determination.//The USSR Academy of Sciences Publishing House, 8, 64-71 (in Russian).

Skoko D., Kotake Y., Sato Y., 1968. Optimum distribution of seismic observation points. V//Bull. Earthquake. Res. Inst., 46(4), 821-840.

Skoko D., Sato Y., Ochi I., Dutta T.K., 1966. Accuracy of the determination of earthquake source parameters as determined by Monte Carlo method: Observation on Indian Network.//Bull. Earthquake. Res. Inst., 44(3), 893-900. 